\title{
LECTURA INFERENCIAL DE LAS ACTITUDES SUBVERSIVAS “CÍNICAS” EN LOS ESTUDIANTES DE EDUCACIÓN DE LA SAN CRISTÓBAL DE HUAMANGA
}

\author{
INFERENTIAL READING OF THE “CYNICAL” SUBVERSIVE \\ ATTITUDES IN THE EDUCATION STUDENTS OF SAN CRISTÓBAL DE \\ HUAMANGA
}

\author{
Adolfo Quispe Arroyo ${ }^{1 *}$, Pedro Huauya Quispe ${ }^{1}$, Edison Laderas Huillcahuari ${ }^{1}$ \\ adolfo.quispe@unsch.edu.pe; pedro.huauya@unsch.edu.pe; edison.laderas@unsch.edu.pe \\ ${ }^{1}$ Universidad Nacional de San Cristóbal de Huamanga, Ayacucho, Perú \\ * Correspondencia: Adolfo Quispe Arroyo. Email: adolfo.quispe@unsch.edu.pe
}

Recibido: 19.05.21 | Aprobado: 01.07.21

\section{RESUMEN}

El presente trabajo de investigación titulado: lectura inferencial de las actitudes subversivas "cínicas" en los estudiantes de educación, se desarrolló con el objetivo de interpretar las actitudes subversivas "cínicas" a través de la lectura inferencial de los estudiantes universitarios en educación. En este sentido se realizó un estudio descriptivo para analizar y describir los resultados de la lectura inferencial referida a las actitudes subversivas de los cínicos, cuyo espacio correspondió a la Facultad de Ciencias de la Educación de la Universidad San Cristóbal de Huamanga. Los estudiantes de la muestra fueron 12 integrantes de la especialidad de Ciencias Sociales y Filosofía de la serie 200. Según la interpretación del rango del instrumento por los puntajes obtenidos se concluye que de los $12(100 \%)$ estudiantes evaluados 07(58,3\%) reconocen las actitudes subversivas de los cínicos y $05(41,7 \%)$ no reconocen las actitudes subversivas.

Palabras claves: Lectura inferencial, cinismo, actitud subversiva.

\section{ABSTRACT}

The present research work entitled: inferential reading of "cynical" subversive attitudes in education students, was developed with the aim of interpreting "cynical" subversive attitudes through the inferential reading of university students in education. In this sense, a descriptive study was carried out to analyze and describe the results of the inferential reading referred to the subversive attitudes of the cynics, whose space corresponded to the Faculty of Education Sciences of the San Cristóbal de Huamanga University. The students in the sample were 12 members of the specialty of Social Sciences and Philosophy of the 200 series. According to the interpretation of the instrument range by the scores obtained, it is concluded that of the $12(100 \%)$ students evaluated $07(58.3 \%)$ recognize the subversive attitudes of the cynics and $05(41.7 \%)$ do not recognize the subversive attitudes.

Keywords: Inferential reading, cynicism, subversive attitude.

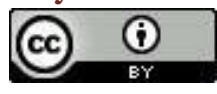




\section{INTRODUCCIÓN}

La comprensión de un texto, en la actividad intelectual de la vida universitaria, es trascendental para continuar con la labor académica en sus dimensiones completas que se espera en sus tres niveles: comprensión literal, inferencial y crítica. Para ello, se recurre a un conjunto de técnicas y métodos en la búsqueda de la precisión y entendimiento de un texto. En el presente caso específicamente de cinismos generan dificultades en su comprensión según los niveles de lectura. Por ello hemos visto por conveniente precisar la lectura inferencial en la comprensión que logran los estudiantes en una lectura seleccionada.

La comprensión inferencial de los estudiantes de Educación es un problema latente en los estudiantes para la comprensión de textos filosóficos, en este caso, "cinismos". A partir de ello se podrá promover, proponer y resaltar la comprensión inferencial en la lectura propuesta, como también puede aplicarse a cualquier otra lectura. Por la naturaleza de la obra se requiere reflexión crítica en algunos casos, inferencias y memoria selectiva y mecanicista en otros. Muchos de los estudiantes no identifican ni detallan el nivel correspondiente de una lectura generando dificultades en la debida interpretación del mensaje del texto.

Hemos realizado la investigación con el objetivo de interpretar las actitudes subversivas "cínicas" a través de una lectura inferencial en atención a nuestra interrogante de la investigación ¿Con la lectura inferencial se reconocen las actitudes subversivas "cínicas" ?, para ello se propuso la siguiente hipótesis tentativa: La lectura inferencial reconoce las actitudes subversivas "cínicas".

La población de nuestra investigación estuvo conformada por los estudiantes de la Universidad Nacional de San Cristóbal de Huamanga, siendo la muestra de 12 estudiantes, cuyo criterio de inclusión fue la especialidad de Ciencias Sociales y Filosofía a criterio del investigador de la Facultad de Ciencias de la Educación y como criterio de exclusión a otras facultades siendo el tipo de muestreo no probabilístico intencional y con un diseño no experimental transversal. El método empleado en la presente investigación fue descriptivo, por la naturaleza y el planteamiento del problema en mención.

La lectura es un proceso de recobro de un tipo de información regulada o ideas arracimadas en un soporte y transmitidas mediante algún tipo de código o convención. Generalmente se manifiestan en tres niveles: literal, inferencial y crítica.

Existen amplios tratados respecto a la lectura y sus manifestaciones, así como teorías sobre su naturaleza e influencias. Siendo el presente un trabajo de lectura inferencial, solo tomamos aspectos centrales y referenciales de la lectura, para profundizar y comparar específicamente los niveles de la comprensión lectora.

Weaver (1994), además complementa tres definiciones para la lectura:

1. Saber leer significa saber pronunciar las palabras escritas.

2. Saber leer significa saber identificar las palabras y el significado de cada una de ellas.

3. Saber leer significa saber extraer y comprender el significado de un texto.

De acuerdo con Bloom (1984, pp.13, 14-16) la lectura y la escritura son: 
... procesos mentales complejos, permiten al estudiante realizar su aprendizaje en los muchos problemas que encontrará viviendo a diario. Estas habilidades se retienen incluso mucho tiempo después de que el individuo se ha olvidado de los muchos detalles específicos del objeto en materia dentro del proceso de aprendizaje guiado en las universidades. Estas habilidades se consideran como un conjunto esencial de características necesarias para el aprendizaje para toda la vida y aspecto clave para adaptarse al cambió continuo del mundo. Estos procesos mentales complejos son también importantes porque ellos alimentan el corazón del motor motivador de la vida del aprendiz.

Así mismo Goodman (1967, pp.126-135) propone un modelo que explica la lectura de adivinación psicolingüística que consiste en:

A medida que los lectores usan claves proporcionadas por el texto lingüístico, utilizan también sus creencias y conocimientos del mundo para poder comprender la lectura. Ellos "adivinan" lo que en el texto por medio de predicciones e inferencias; son selectivos en el uso de las claves del texto y vigilan la aparición de claves contradictorias a sus "suposiciones". Por tanto, la lectura efectiva no consiste en el reconocimiento exacto de palabras sino en un acercamiento al significado global del texto. La lectura eficaz, por su parte, es usar un número apenas suficiente de las claves disponibles para entender el texto, dependiendo del conocimiento que el lector aporta a la lectura.

Lo que es leer para Jolibert \& Jacob (1998, p.208):

Leer es leer de golpe comprensivamente, desarrollando-en una situación real de uso- una intensa actividad de búsqueda del sentido del texto. Es una actividad compleja de tratamiento de varias informaciones por parte de la inteligencia. Es un proceso dinámico de construcción cognitiva, ligado a la necesidad de actuar, en el cual además intervienen la afectividad y las relaciones sociales.

El lector busca, desde el inicio, el sentido del texto, utilizando-para construirlodistintos procesos mentales y coordinando todo tipo de indicios (contexto, tipo de texto, título, marcas gramaticales significativas, palabras, letras, etc.).

Entonces la lectura simboliza, además de la decodificación o descifrado de signos gráficos, un acto de razonamiento hacia la construcción de una dilucidación de un mensaje escrito partiendo de un texto.

En filosofía, podemos considerar lectura el aprendizaje de filosofía o el acto de filosofar a partir de los proporcionados por los textos filosóficos de autores clásicos o aspirantes a ello. Es decir, leer e interpretar obras diferentes de autores clásicos o modernos para contextualizar y comprenderlo. La labor de lectura requiere esfuerzo, voluntad, disciplina y una serie de técnicas que requiere principalmente tiempo; leer cantidades significativas no se consigue espontáneamente y en breve tiempo, puede llevarnos varios años de disciplina constante. Leer a la brevedad posible las principales obras de filósofos clásicos y modernos resulta provechoso para quien se esté iniciando en filosofía, coger fragmentos breves, exorbitantes, escandalosos, delirantes e irreverentes pueden iniciar en la lectura filosófica. 
De esta manera, el estudiante no sólo estará aprendiendo y contextualizando el mensaje del filósofo clásico y moderno, sino además se estará iniciando en la filosofía propiamente dicha. Esta actividad lleva a entender y asumir una actitud reflexiva y crítica como consecuencia de la lectura de un texto filosófico.

La comprensión del texto es analizar un fragmento breve de una obra filosófica para el presente estudio. En dicho análisis es conveniente tratar una serie de cuestiones tales como: sobre qué tema gira el texto, qué problemas aborda, cuál es la tesis que se sostiene, cuáles son los términos más relevantes que aparecen en el texto, cómo debe situarse el texto dentro de la obra del autor, qué circunstancias histórico-ideológicas condicionaron la obra, qué posibles relaciones pueden existir entre el texto en cuestión y otros textos filosóficos del mismo autor o de otros autores. En este caso la lectura específica de Cinismos que desbordan posibles actitudes subversivas, abordado desde el nivel de la lectura inferencial.

La comprensión del texto filosófico conlleva el análisis de un fragmento seleccionado de un texto clásico o moderno de un autor. En este caso Cinismos y las posibles actitudes subversivas que supone dilucidar las ideas principales y las tesis provocadoras que podrían estar presente en el mensaje. Formular interrogantes, generar comparaciones, contextualizar las ideas para comprender al filósofo en su tiempo y en el presente viene a ser la lectura filosófica.

Estos análisis se enfocan con la lectura inferencial como un nivel de lectura interpretativo y conclusivo.

La atención está puesta en la comprensión e identificación de la lectura: cinismos donde se trata de localizar y concluir en sus posibles actitudes subversivas.

¿Se puede afirmar que los cínicos eran subversivos? Onfray (2005, p. 222) refiere: “...escuela filosófica subversiva señalando que los culpables de las gracias insolentes y quienes corrompieron el espíritu cínico fueron los seguidores de Antístenes”.

Un proceso cognitivo complejo que requiere un análisis muy profundo en sus interpretaciones según los resultados de las posibles actitudes subversivas se observa que de los $12(100 \%)$ estudiantes evaluados 07 (58,3\%) reconocen las actitudes subversivas de los cínicos y $05(41,7 \%)$ no reconocen las actitudes subversivas de los cínicos.

Reconocer no implica que sean de estas características o se identifiquen como tales, pero en cuanto a las actitudes que asumen en la antigüedad, los filósofos llamados perros, serían de alguna forma justificadas o entendidas por el porcentaje que mencionamos. Mientras en un porcentaje menor no aprueban o no coinciden con estas actitudes cínicas de la antigüedad.

\section{METODOLOGÍA}

Tipo de investigación: Teórica; nivel: descriptiva; diseño: no experimental; nivel social, espacial y temporal: estudiantes de la Universidad Nacional de "San Cristóbal de Huamanga" - Ayacucho, 2019; población objetiva: estudiantes; muestreo: no probabilístico a criterio del investigador (12); criterio de inclusión: estudiantes de la especialidad de Ciencias Sociales y Filosofía serie 200 de la Facultad de Ciencias de la 
Educación; criterios de exclusión: estudiantes de otras series y otras facultades; método: descriptivo y analítico; técnica e instrumento: evaluación de la lectura Cinismos y su respectivo instrumento prueba de comprensión de las actitudes subversivas cínicas; técnicas de procesamiento de datos: paquete estadístico excel 2019; representado en la tabla 1.

\section{RESULTADOS}

\section{Tabla 1}

Lectura inferencial de los estudiantes de Educación de las actitudes subversivas "cinicas"

\begin{tabular}{llc}
\hline LECTURA INFERENCIAL & $\begin{array}{l}\text { Lectura inferencial de las actitudes } \\
\text { subversivas “cínicas" en los estudiantes } \\
\text { de la FCE - UNSCH, 2019 }\end{array}$ \\
\cline { 2 - 3 } & $\mathbf{\mathbf { N } ^ { \mathbf { 0 } }}$ & $\mathbf{\%}$ \\
\hline Actitudes subversivas & 07 & 58.3 \\
Actitudes no subversivas & 05 & 41.7 \\
\hline TOTAL & $\mathbf{1 2}$ & $\mathbf{1 0 0}$ \\
\hline
\end{tabular}

Se observa en el cuadro que de los $12(100 \%)$ estudiantes evaluados en la EFP de Educación Secundaria de la especialidad de Ciencias Sociales y Filosofía 07(58,3 \%) reconocen las actitudes subversivas de los cínicos y 05 (41,7\%) no reconocen las actitudes subversivas de los mismos.

Reconocer las actitudes no implica que sean de estas características o se identifican como tal, pero en cuanto a las actitudes que asumen en la antigüedad, los filósofos llamados perros, serían de alguna forma justificadas o entendidas por el porcentaje referido. Mientras en un porcentaje menor no reconocen o no coinciden con estas actitudes cínicas de la antigüedad.

Las actitudes subversivas, según el momento histórico se puede entender que quieren subvertir o cambiar el sistema político y social vigente en una determinada época, luego tal época querrá perennizarse para evitar nuevos paradigmas de quienes propagan otras formas de organización social y política, siendo calificados de subversivos los que promueven o no coinciden con el sistema social, político, moral y económico vigente.

La comprensión lectora es una actividad constructiva compleja de carácter estratégico, que implica la interacción entre las características del lector y del texto, dentro de un contexto determinado. (Díaz y Hernández, 1999).

Comprender un texto no es descubrir el significado detallado de palabra seguida de oraciones ni siquiera de las frases, o del contenido general del texto; por el contrario busca generar una figura conceptual, categórica, representativa mental de las ideas motrices de un texto. Se empieza con producir un modelo mental del mensaje del texto sea referido a lo ideal o real para que termine cobrando sentido u organización lógica. Durante el transcurso de la comprensión el lector elabora y actualiza modelos mentales de modo continuo (Cooper, 1990). 
En el nivel inferencial el estudiante obtiene información nueva a partir de fundamentos explícitos del texto. Esta información se refiere a un tema estudiado, a las ideas principales y secundarias, a las ilustraciones o a las terminaciones. El estudiante deduce a partir de metáforas, alegorías, provocaciones e insinuaciones subliminales de un mensaje. Mediante el nivel inferencial se determina el propósito comunicativo y se establecen relaciones complejas entre dos o más textos (Pinzás, 2006)

En el nivel inferencial intervienen procesos cognitivos de mayor complejidad que los del nivel literal. Por ejemplo, se activan procesos como la organización, la discriminación, la interpretación, la síntesis, la abstracción, entre otros.

Por otro lado, el cinismo como filosofía es un estilo de vida y de pensar, así como de expresarse. Hoy son destacados en gran medida por sus frases y anécdotas que fueron transferidos en forma de referencias. Las ocurrencias más famosas de los cínicos se encuentran en la obra de Diógenes Laercio, referencia imprescindible para entender a los cínicos y a sus contemporáneos.

Por otro lado, es de interés la obra de Michael Onfray referido a los cínicos a quienes describe como expertos en alegorías, ironías, provocaciones, sátiras, burlas, parodias a lo que podríamos identificar con actitudes subversivas.

Según narraciones históricas, Diógenes el cínico, abandonó Sinope porque fueron acusados, tanto él como su padre, de falsificar monedas. Por lo que su padre habría sido encarcelado y Diógenes tuvo que alejarse rápidamente para no correr la misma suerte. Por ello se relaciona su actitud de transvaloración, invalidando los valores conservadores y practicando otros totalmente opuestos a los practicados en su momento. Las prácticas cínicas fueron incisivamente naturalistas y provocativamente irónicas que se convertirían en el distintivo de los cínicos. Por ello se les acusará de ser sospechosamente subversivos, pues trastocaron la organización misma de la sociedad esclavista.

Anular los valores y la moral vigente de la época fue una osadía única de los cínicos que pueden considerarse como actos subversivos. Ellos practicaron otros valores y manifestaron moral diferente en una actitud rebelde y despectiva contra la sociedad de su tiempo. Ridiculizaron las necesidades, costumbres y conceptos vigentes para declararse naturalistas, ciudadanos del mundo y por ende libres que no reconocían autoridad alguna. Estas actitudes cínicas escandalizaban a la sociedad en general y a sus pensadores y autoridades en particular.

Para los cínicos, la naturaleza nos brinda todo lo necesario y la moral promovida por la sociedad decadente nos esclaviza, por ello debemos ser libres y austeros naturales para despojarnos de deseos creados o artificiales, así alcanzaremos la tranquilidad y en seguida la felicidad.

Las actitudes subversivas, según el momento histórico se puede entender que quieren subvertir o cambiar el sistema político, económico y social vigente en una determinada época, luego tal sistema querrá perennizarse para evitar nuevos paradigmas de quienes propagan otras formas de organización social y política, siendo calificados de subversivos los que promueven o no coinciden con el sistema social, político, moral y económico vigente. ¿Se puede afirmar que los cínicos eran subversivos? Onfray (2005, p. 
222) reconoce: “...escuela filosófica subversiva señalando que los culpables de las gracias insolentes y quienes corrompieron el espíritu cínico fueron los seguidores de Antístenes”.

Onfray (2005) reconoce el carácter subversivo de las actitudes cínicas, así mismo considera que fueron los primeros libertarios y maestros de la ironía, la provocación y los rivales directos de los llamados clásico como: Sócrates, Platón y Aristóteles. Por otro lado para Laercio (2002) los cínicos fueron hombres uranios de anécdotas solitarias y poetas ambulantes que recorrían la vida en contra de la corriente común de lo que se pensaba aquel momento, pero no nos habla en ningún momento de posibles actitudes subversivas.

En el diccionario soviético de filosofía (1965) refiere al mayor representante del cinismo: Diógenes el cínico y describen que:

Llevó las concepciones de su maestro hasta las consecuencias más extremas. Como Antístenes, reconocía sólo lo singular y criticaba la doctrina de Platón sobre las ideas como esencias generales. Rechazaba todos los progresos de la civilización y exhortaba a limitar la satisfacción de las necesidades a las indispensables y de carácter animal. Rechazó también el politeísmo con todos los cultos religiosos, por considerarlos instituciones puramente humanas y superfluas. Diógenes criticaba las diferencias de clase, predicaba el ascetismo. La tradición le ha atribuido osadía e independencia ante los poderosos, desdén por las normas de conducta social; según lo que de él se ha contado, vivía en un tonel (barril). Es poco probable, sin embargo, que su imagen de cínico sin rebozo, en extremo pintoresca, corresponda plenamente a la realidad, pues son contradictorios los datos que sobre este particular se poseen (s/p).

Antístenes era el maestro de Diógenes, en lo descrito se observa que resaltan las actitudes contrarias a las preponderantes de la época.

Por los resultados obtenidos la mayoría identifica inferencialmente las actitudes subversivas de los cínicos como los autores los describen, mientras la minoría no reconoce tales actitudes y no coinciden con los autores referidos.

En conclusión, podemos afirmar que los estudiantes evaluados en su mayoría reconocen las actitudes subversivas de los cínicos y en minoría no reconocen las actitudes subversivas de los mismos. Esto implica también el nivel de lectura inferencial que poseen los estudiantes, pues previo al análisis, reflexión y crítica del texto leído asumen las respuestas respectivas.

Reconocer las actitudes no implica que acepten o se identifiquen con estas características, pero en cuanto a las actitudes que asumen en la antigüedad, los filósofos llamados perros, serían de alguna forma justificadas o entendidas por el porcentaje que mencionamos. Mientras en un porcentaje menor no reconocen actitudes subversivas cínicas de la antigüedad.

Las actitudes subversivas son de aquellos que quieren subvertir o cambiar el sistema político, económico y social vigente en una determinada época, luego tal sistema se resistirá a nuevos paradigmas que propagan otras formas de organización social, económica y política, siendo calificados de subversivos los que promueven o no coinciden con el sistema social, político, moral y económico vigente. 
La lectura inferencial como nivel de comprensión de lectura asume críticas, reflexiones, analogías y análisis en general del texto leído, ubicando el contexto histórico y las concepciones que rigen esos tiempos que reflejan en dicha lectura.

Los cínicos, filósofos llamados perros de Grecia antigua, fueron los primeros en desafiar al sistema político, social y moral de la época de una manera libertaria, rebelde y en práctica cotidiana. Se mofaban de la moral conservadora y convencional, no reconocían autoridad alguna, no se consideraban esclavos de las leyes, imitaban algunas conductas de los perros. De allí se les conocía como los filósofos perros, pues el término

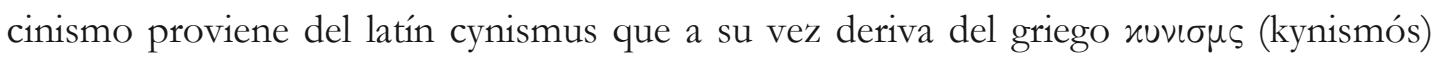

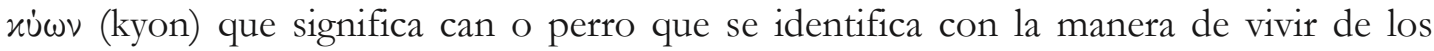
filósofos cínicos.

La consideración fundamental de los cínicos respecto al hombre debe ser la virtud a lograr, solo a través de ella alcanzaremos la felicidad. Los cínicos rechazaban normas y convenciones conservadoras propias de la sociedad; objetaban la fama, mostraban cierto desprecio al poder o la riqueza, ya que estos valores superficiales desnaturalizados, dictados por acuerdos sociales nos alejan del camino virtuoso, por ende, nos desvirtúa de nuestra naturaleza.

El cínico apenas cubría naturalmente sus necesidades básicas; despreocupado de su higiene y su forma de vestimenta, se despojó de los bienes y las riquezas, carecía de familia formal y sustento, y se dedicaba a advertir provocativamente la trivialidad y la putrefacción de la sociedad de su tiempo. El cínico, pues, gozaba de gran libertad. Estas y otras características son descritas minuciosamente por Michael Onfray en su obra: Cinismos, retrato de los filósofos llamados perros (2005), cuya lectura inferencial de ella y de otras obras nos muestran los resultados descritos.

\section{ORCID}

Adolfo Quispe Arroyo: Universidad Nacional de San Cristóbal de Huamanga, Ayacucho, Perú (iD

Pedro Huauya Quispe: Universidad Nacional de San Cristóbal de Huamanga, Ayacucho, Perú

Edison Laderas Huillcahuari: Universidad Nacional de San Cristóbal de Huamanga, Ayacucho, Perú

\section{FUENTE DE FINANCIAMIENTO}

El estudio fue autofinanciado.

\section{CONFLICTOS DE INTERÉS}

Los autores expresan que no existen conflictos de interés.

\section{AGRADECIMIENTO}

No aplica.

\section{PROCESO DE REVISIÓN}

Este estudio ha sido revisado por pares externos en modalidad de doble ciego. 


\section{DECLARACIÓN DE DISPONIBILIDAD DE DATOS:}

No aplica

\section{REFERENCIAS BIBLIOGRÁFICAS}

Bloom, B. S. (1984) The 2-sigma problem: The search for methods of group instruction as effective as one-to-one tutoring. Educational Researcher.

Cooper, J.D (1990) Cómo mejorar la comprensión lectora. Visor - MEC, Madrid.

Díaz B., F. y Hernández R., G. (1999) Estrategias docentes para un aprendizaje significativo. Edit. Mc Graw-Hill, México.

Jolibert \& Jacob (1998) Lo que es leer. Edit. Mc Graw-Hill, México.

Goodman, K.S. (1967) Reading: a psycholinguistic guessing game. Journal of the Reading Specialist.

Laercio, Diógenes (2002) Vidas de filósofos ilustres. Edit. Omega, Barcelona.

Onfray, Michael (2005) Cinismos: retrato de los filósofos llamados perros. Ed. Paidós, Barcelona.

Pinzás García, Juana (2006) Comprensión lectora. FIMART, Lima.

Pueblos Unidos (1965) Diccionario soviético de filosofía. Edic. Pueblos unidos, Montevideo.

Weaver (1994) Aspectos de la comprensión literaria. Universidad de Baylor.

\section{CITAR COMO:}

Quispe Arroyo, A., Huauya Quispe, P., \& Laderas Huillcahuari, E. (2021). Lectura inferencial de las actitudes subversivas “cínicas” en los estudiantes de Educación de la San Cristóbal de Huamanga. Puriq, 4, e197. https://doi.org/10.37073/puriq.4.1.197 